\title{
Disputas cognitivas e exercício da capacidade crítica: o caso dos conflitos ambientais no Brasil
}

HENRI AGSELRAD *

\section{Resumo}

O debate sobre as questões ambientais incide sobre objetos complexos, em torno ao qual se enfrentam interesses contraditórios, entrecruzam-se competências múltiplas, desenvolvem-se controvérsias científicas e políticas. A temporalidade da controvérsia científica não é, porém, a mesma da temporalidade do debate político. Uma incerteza se produz, dado que o saber especializado não consegue fechar o debate, mas, sim tenderia a abri-lo com relação a valores, para a reflexividade e não necessariamente para um acordo. $\mathrm{O}$ presente texto propõe-se a discutir as condições em que o campo de forças em que se instaura o conflito político-cognitivo em torno aos chamados impactos ambientais habilita-se a garantir a autonomia da produção científica.

Palavras-chave: Conflitos ambientais. Campo científico. Campo político. Desenvolvimento. Conflitos cognitivos.

\footnotetext{
* Universidade Federal do Rio de Janeiro (UFRJ), Rio de Janeiro - RJ, Brasil.
} 
Knowledge disputes and the exercise of critical capacity: the case of environmental conflicts in Brazil

\section{Abstract}

The environmental debate focuses on complex subjects, about which contradictory interests confront themselves and different types of knowledge contribute to scientific and political controversies. But the temporality of scientific controversies is not the same as that of politics. So, uncertainty is produced, because specialized knowledge is not able to close de debate, but, frequently, finishes by opening it to values, to reflexivity and not, necessarily, to agreement. This article aims at discussing the conditions for scientific autonomy to be exercised in the field of forces where political and knowledge conflicts on environmental impacts are being developed.

Key-words: Environmental conflicts. Scientific field. Political field. Development. Knowledge conflicts.

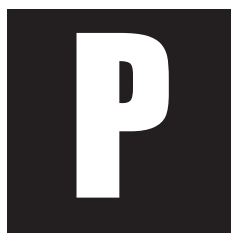

retendo aqui trazer algumas considerações sobre as relações entre o campo político e o campo científico, notadamente no que diz respeito às possibilidades de se produzir um pensamento autônomo que problematize a prevalência de categorias-chave como "desenvolvimento", assim como a epistemologia política que hoje encontra-se subjacente aos esforços de legitimação dos tipos de projetos desenvolvimentistas em curso, desde o início dos anos 2000, em vários países da América Latina. Como nos sugere Stengers (1997), em contextos de despolitização - de silenciamento relativo das possibilidades de problematização da realidade como ela está dada - a ciência é, por vezes, utilizada para definir os limites tidos por objetivos no interior dos quais se poderia dar o exercício das escolhas políticas. Dados os limites fixados por este suposto saber objetivo, caberia discutir apenas o resíduo que restaria para a deliberação demo- 
crática no âmbito da ação política. Isso posto, a autora nos provoca: e se invertêssemos a assertiva e disséssemos, ao contrário, que a confiabilidade e o interesse dos saberes que uma sociedade produz é que refletem a qualidade de seu funcionamento democrático? Ou seja, que quanto mais amplo for o campo problematizado da vida social - aquele acionado na esfera política -, maior será a contribuição que o campo cientifico poderá dar. Esta proposição oferece uma boa configuração de base para o equacionamento de nosso problema: em democracias restringidas, vigorando em sociedades desiguais e, em grande parte, submetidas a poderosos interesses econômicos, o saber suscetível de ser produzido tenderia a ser, em geral, proporcionalmente pouco "confiável e interessante". O desafio que, consequentemente, para nós se colocaria, é duplo - o de superar os constrangimentos à produção de um conhecimento autônomo e interessante no campo científico e, desde o lugar que ocupam os pesquisadores, o de problematizar as forças despolitizadoras que se têm, desde o início das reformas neoliberais dos Estados nacionais, abatido sobre as sociedades.

Segundo Edward Said, uma das principais atividades do intelectual seria a de questionar o consenso em torno da objetividade dos fatos, da pretensão de se afirmar como universal o ponto de vista particular dos dominantes. Ao intelectual, diz ele, não caberia mostrar que está certo,

mas tentar induzir uma mudança no clima moral do debate, de modo a que a punição injusta de povos ou indivíduos seja evitada, que o reconhecimento de liberdades e direitos democráticos seja estabelecido como norma para todos e não injustamente para um punhado de eleitos (Said, 2005, p. 102).

Operando uma analogia da crítica que faz Said à dominação colonial, poderíamos dizer que certa forma de colonialismo interno ${ }^{1}$ se exer-

\footnotetext{
${ }^{1}$ Usada pela primeira vez por C. Wright Mills (1963, p. 154), a expressão colonialismo interno foi retomada por González Casanova (1965), que sustentou a tese de que davam-se relações sociais de tipo colonial no interior de uma mesma nação, na medida em que há nela uma
} 
ce sobre os sujeitos atingidos pelo projeto desenvolvimentista corrente, forma esta que vai ganhando sentido à medida em que observam-se, ao longo do continente latino-americano, processos de reconfiguração das lutas por terras em lutas por território e de etnicização de parte das lutas ambientais e fundiárias (Guedes, 2013).

O "desenvolvimento" é, com efeito, apresentado como bom para todos - a nação, os empresários e o povo. Mas a desconsideração do ponto de vista dos que são atingidos negativamente pelos impactos do desenvolvimento supõe uma hierarquização de direitos e culturas, a cultura desenvolvimentista tendo precedência sobre as demais². Parafraseando Said, poderíamos dizer que da legitimação de tal processo estariam participando os intelectuais que aderem ao realismo político da necessidade de afirmação do país na competição internacional, que fecham os olhos para a negação

heterogeneidade étnica, em que se ligam determinadas etnias com os grupos e classes dominantes, e outras com os dominados. Em1969, em seus ensaios sobre Sociologia da exploração (González Casanova, 1987), o autor procurou precisar os vínculos entre classes, imperialismo e colonialismo interno, ampliando o alcance do termo e o relacionando com as diferenças regionais na exploração dos trabalhadores e com as transferências de excedente das regióes dominadas às dominantes. (González Casanova, 2007, p.7-8). Cardoso de Oliveira, por sua vez, assinala como, no começo dos anos 1960, as ideias de Georges Balandier, expressas no livro La sociologie de l'Afrique noire, foram fundamentais para que ele próprio começasse a trabalhar com a noção de colonialismo interno. cf. Roberto Cardoso de Oliveira, Entrevista concedida a Carlos Fausto e Yonne Leite (Museu Nacional/UFRJ) e Carmen Weingrill e Vera Rita da Costa (Ciência Hoje) Disponível em <http://www.canalciencia.ibict.br/notaveis/livros/ roberto_cardoso_de_oliveira_39.html>.Acesso em: 3 dez. 2013.

${ }^{2}$ Relatórios de viajantes que exploravam as condições de implantação de agricultura comercial em áreas de fronteira são ilustrativos da "epistemologia" da dominação. Eis o relato de um naturalista caracterizando culturas locais encontradas no Mato Grosso em 1922: (...) é fácil viver nestas plagas ubertosas porque as raças mestiças tão comuns aqui herdaram os hábitos inertes e descuidados de seus antepassados índios e africanos: apenas alguns têm ambição de erguer-se da vida animal (...); para o Estado, são verdadeiro zero, quase nada trazem ao mercado e ainda menos levam para casa; vivem ao deus dará, satisfeitos porque têm provisões para um dia e palhoça que os abrigue. Hão de morrer à medida que da terra se forem apossando gentes mais industriosas. Pois que morram - é o único serviço que podem prestar ao país. Smith, H. Do Rio de Janeiro a Cuyaba: notas de um naturalista, 1922, p. 43 apud Malta Castro e Guedes Galetti (1994, p.20). 
de direitos aos atingidos, que adotam a estrutura conceitual do desenvolvimentismo governamental e empresarial, que disseminam as verdades construídas sobre a benignidade coletiva dos grandes projetos de investimento, negando aos atingidos direitos iguais aos dos beneficiários dos negócios do desenvolvimento, estabelecendo hierarquias entre os diferentes ou as dissimulando sob a retórica do bem comum, quando o que está em jogo são recursos econômico-territoriais e poder estratégico para capitais e Estados.

Sabemos que o campo científico é o cenário de uma ação política onde as teorias se confrontam e que, por trás das escolhas epistemológicas, há forças sociais; e também que este campo científico retraduz, sob formas específicas, as pressões sociais externas a ele. Ou seja, entre o trabalho científico e o contexto da produção da ciência existe um microcosmo intermediário relativamente autônomo dotado de leis próprias, ainda que submetido às leis gerais do macrocosmo social; as pressões externas são, por sua vez, mediadas pela estrutura e pelas propriedades do campo científico (Bourdieu, 2003). Ora, nesta perspectiva, não deveríamos excluir a hipótese de que sejam tais tipos de pressões externas que estejam levando certos atores a utilizar a linguagem científica para sugerir, por exemplo, que o caso brasileiro, na primeira década dos anos 2000, é um exemplo exitoso de desenvolvimento com especialização na exportação de recursos naturais, com mecanismos de transferência da alta produtividade dos setores especializados em recursos naturais para o restante da economia, com aprendizado, acumulação de conhecimento e geração de externalidades para o restante da economia. É o que tem sustentado também, por exemplo, uma literatura internacional recente que questiona a tese da "maldição dos recursos naturais", apontando casos exitosos como EUA, Escandinávia, Austrália e Canadá. Tais esforços argumentativos somam-se, ademais, aos daqueles que alegavam, desde o início da liberalização dos mercados, ser este o único modelo possível para as economias periféricas. 
Ora, intervir para mudar o clima moral deste debate implicaria em fazer a ruptura com o senso comum que sugere que o atual modelo de desenvolvimento - baseado na exportação de commodities - é o único possível e que ele se impõe inelutavelmente aos governos. Significaria mostrar que, ao contrário, os agentes de seguidos governos têm optado por ele, mesmo quando a crise internacional propiciou a busca de novos caminhos; que o que se tem entendido por "desenvolvimento" na América Latina, após as reformas neoliberais dos Estados nacionais, tem se mostrado um mecanismo de geração concentrada de riqueza que se tem apoiado em processos de expropriação, métodos conhecidos da "acumulação primitiva" que destroem direitos de grupos sociais subalternos; que a adoção de tal modelo não se dá por processos determinísticos, mas por mecanismos históricos que criam, eventualmente, as condições subjetivas de sua aceitação; que as deslocalizações de capitais e unidades produtivas são, no atual regime de capitalismo flexível, os mecanismos de subjetivação das condições de competição inter-local, instituindo a concorrência entre os trabaIhadores de todo o mundo, assim como entre as (des)regulações ambientais operadas pelos diferentes Estados nacionais e poderes locais (Acselrad e Bezerra, 2010); que sob o discurso do "neo-desenvolvimentismo", o mercado de terras no Brasil tem desempenhado papel estratégico na reestruturação do capitalismo agrário mundial, assim como, para as corporações internacionalizadas em geral, nesse terreno encontram-se em expansão as fronteiras da exploração mineral, dos recursos energéticos e da água; que os conflitos ambientais que têm-se manifestado nos territórios em questão são a expressão da emergência de críticas aos projetos de desenvolvimento que são enunciadas por sujeitos coletivos que se veem ameaçados ou em vias de expropriação, e cujas manifestações e vocalizações críticas certos pesquisadores procuram tornar visíveis e audíveis na esfera pública da ciência e, em certos casos, fora dela (vide a este respeito a experiência do Painel de Especialistas que pronunciou-se no caso da UHE de Belo Monte) (Magalhães, Hernandez, 2009). 
O trabalho científico de ruptura com o senso comum desenvolvimentista requer, por certo, um esforço de construção de objetos teóricos de modo a problematizar, nos termos da sociologia do conhecimento científico, "os conjuntos significativos que organizam um domínio de saber", a "maquinaria conceitual", os "hábitos de pensamento", o universo mental dos pesquisadores e o conjunto de esquemas ideacionais que lhes fornecem correntemente a matéria a ser pensada. Trata-se, assim, de operar "um olhar reflexivo que se interroga sobre o próprio olhar científico em vias de se constituir" (Gaboriau, 2008). Esse é o esforço que poderia configurar um movimento crítico no campo científico, encarnando uma postura intelectual apta a mudar, nos termos evocados por Said (2005), o clima moral do debate, em nosso caso, sobre "desenvolvimento".

Quais são as condições que desafiam a capacidade da Universidade preencher hoje este papel? Suponhamos, com a Sociologia pragmática, que o exercício da capacidade crítica $^{3}$ se destaca sobre um fundo de adesão tácita à realidade corrente tomada por dada, onde operam as instituições com as quais se confronta o esforço crítico. Uma inquietação constante sobre "o que é e o que vale" existiria, pois, em estado latente nas situações onde aparentemente reina a ordem (Boltanski, 2009); e a crítica só ganharia sentido com relação à ordem que ela pretende por em crise, enquanto os dispositivos que asseguram a manutenção da ordem só ganhariam sentido quando ameaçados pela possibilidade da critica. A

\footnotetext{
${ }^{3}$ Não desconsideramos o fato que há uma variedade de posturas críticas, mais ou menos radicais, entre as quais algumas podem, inclusive, ser recuperadas ou descaracterizadas pelas forças hegemônicas. O que pretendemos ressaltar aqui, porém, são as condições para o exercício da função crítica, para as quais não basta a vigência de uma racionalidade e de uma concorrência entre ideias. Para que se possa assegurar a conservação do espaço público como um bem comum, cabe aos agentes do campo intelectual, em acréscimo, um comprometimento com a própria reponsabilidade a respeito da conservação deste bem. cf. Vincent Descombes, Quand la mauvaise critique chasse la bonne..., in Tracés, hors-série, 2008, p. 45-69.
} 
crítica do desenvolvimentismo, que nos ocupa, instabilizaria, por certo, a realidade; introduziria incerteza naquilo que é - a produção crescente de bens para o consumo material induzido por esforços publicitários de venda e obsolescência programada - e no desenvolvimento como aquilo que deve ser: a incerteza incidiria sobre a semântica - o sentido da noção de progresso - e sobre a valoração - sobre aquilo que importa, que tem valor.

As dimensões sócio-ecológicas do desenvolvimento capitalista, por exemplo, tal como evidenciado pelos historiadores da "acumulação primitiva" ou, mais recentemente, pelos analistas da chamada "acumulação por despossessão" (Harvey, 2004), pressupõe a privatização de fato - via de regra, silenciada - de espaços de uso comum. As instituições correntes das chamadas "políticas de meio ambiente" - criadas no interior de grande parte dos Estados nacionais a partir dos anos 1970 - concorrem para normalizar, de algum modo, tal privatização do comum, definindo o que poderíamos chamar de "poluição legítima", negociando as condições gerais não-mercantis de produção compatíveis com a continuidade da competição intercapitalista. A crítica da "ambientalidade" específica do capitalismo, notadamente quando denuncia a privatização de fato do espaço não-mercantil comum, é, por sua vez, objeto de esforços continuados destinados a sua neutralização por estratégias ditas de "modernização ecológica", que procuram fazer do "meio ambiente" uma oportunidade de negócios, celebrando a economia de mercado, o progresso técnico e o consenso político - a questão ambiental sendo aí apresentada, correntemente, nos termos de como uma causa universal que remete a um planeta uno e a um futuro comum. 


\section{Considerações sobre campo político, reformas liberais e capacidade crítica}

Cabe perguntar: como as condições do exercício desta crítica têm sido reconfiguradas - e, via de regra, restringidas - de modo a favorecer a reprodução de tal modelo? No campo político, nas atuais condições de liberalização dos mercados, os imperativos da competitividade têm sido apresentados como razão maior para se atenuar os cuidados com os impactos sociais e ambientais, moderar o ânimo preventivo, justificar fórmulas compensatórias e, eventualmente, ignorar, desqualificar, condenar ou obscurecer evidências de danos produzidos. O capitalismo liberalizado procura, assim, capturar os atores sociais no interior de "alternativas infernais" - situações que parecem não deixar outra escolha além da resignação ou da denúncia impotente ante a guerra econômica incontornável (Stengers; Pignarre, 2005, p. 39-40). O imperativo da aceitação substitui a política pela submissão - as "alternativas infernais" impõem-se como norma, regra de juízo que produz a medida comum das coisas, mecanismo de disciplinamento e controle (Ewald, 1993:104), que faz com que os indivíduos se vejam aprisionados nos imperativos da competitividade, nos requisitos de serem capazes de atrair sobre si e suas localidades os investimentos disponíveis no mercado. Mas como essas "alternativas infernais" são geradas e impostas? As alternativas infernais seriam produzidas, como sugerem abordagens da sociologia histórica, através da reorganização permanente do modo de funcionamento do sistema, fazendo com que sejam neutralizados os poderes dos que têm outras lógicas por referência (Stengers; Pignarre, 2005, p. 39-40). Através das formas reorganizadas do sistema, o movimento dos investimentos incute a norma - os atributos disciplinares que justificam a localização e o perfil dos negócios.

No campo jurídico, as legislações são flexibilizadas, geralmente em nome da necessidade de viabilizar licenciamentos ditos "ágeis e desburocratizados", que tendem a desconsiderar os danos sociais e ambien- 
tais, particularmente quando estes afetam mais que proporcionalmente categorias sociais despossuídos e grupos étnicos. O direito burocrático e regulamentar do meio ambiente evoca, assim, irresistivelmente, uma tapeçaria de Penélope onde o que é feito de dia é desfeito à noite (Ost, 1994). A "ambientalização" dos Estados nacionais mostra-se truncada configurada como uma ação ou obra interrompida, deixada incompleta ou impedida de ser levada a cabo, dada sua coincidência com os processos de despolitização de uma série de ações governativas e a ausência de base social capaz de fazer representar no interior do Estado a perspectiva dos que recusam a inelutabilidade das políticas de apoio a uma acumulação intensiva em território e recursos ambientais.

Tecnologias de resolução negociada de conflitos investem, paralelamente, no tratamento caso a caso dos litígios, assim como em sua despolitização, de modo a que estes não contaminem a esfera política, colocando eventualmente em causa o próprio modelo de desenvolvimento como um todo, alimentando uma discussão de conjunto, por exemplo, sobre a lógica que articula a construção de grandes barragens, a atividade mineradora e as dinâmicas especulativas nos territórios. Em meados dos anos 1990, o Ministro do Meio Ambiente da Colômbia declarou: "é necessário deixar a Natureza fora do conflito social" (Palacios, 2002). Um ex-presidente do Chile, em 2003, ecoou: Um país sem coesão social é conflitivo. Um país conflitivo não é competitivo. Para competir no exterior se faz necessária a coesão social ${ }^{4}$. Procura-se, assim, individualizar os problemas gerais e solucioná-los em sua particularidade, pondo-se como meta a obtenção da paz empresarial através do encaminhamento das reivindicações e protestos em direção a uma solução que dê "satisfação às partes" - ditas win-win, objetivo que é bem traduzido no título de um clássico manual da negociação de conflitos da Universidade de Harvard

${ }^{4}$ Folha de SP, 17/8/2003, p. A27. 
- "Como obter o sim". A criação de departamentos empresariais de antecipação da conflitualidade procura prevenir que conflitos "metodologicamente" difíceis de serem transformados ou resolvidos em uma transação econômica ${ }^{5}$ - tais como aqueles tendo por objeto espaços não-mercantis e áreas de uso comum - realizem toda a sua potência política.

A chantagem locacional dos investimentos (Acselrad e Bezerra, 2010) - mecanismo através do qual os capitais móveis pressionam os poderes locais e os atores sociais menos móveis pela obtenção das condições sociais e ambientais as mais vantajosas para sua rentabilização - configura uma coalizão desenvolvimentista que opera uma espécie de "servidão voluntária produzida", que, através das desregulações, faz dos detentores do poder de investir quase-sujeitos das políticas urbanísticas, ambientais e, em alguma medida, científicas ${ }^{6}$. Com a imposição das condições mais desejáveis para

\footnotetext{
${ }^{5}$ Vide, para um argumento invertido, a formulação liberal de Abba Lerner (1972).

${ }^{6}$ Kalecki (1943) já teorizava a transformação da força econômica do capital em força política: Entre os determinantes das decisões de investimento, Kalecki destaca a disposição dos capitais a exercerem um controle indireto sobre as políticas governamentais. Os empresários combatem políticas governamentais de criação de emprego para não perderem o poder de manipular o "clima dos negócios" ameaçando o Estado com o desemprego e a instabilidade social - ou seja, fazendo de seu poder de investir uma força direta sobre o Estado. O "estado de confiança" é a variável através da qual o capital exerce um controle sobre as políticas governamentais. Para o capital, tudo que abala a sua capacidade de manipular o "estado de confiança" - o clima dos negócios - deve ser evitado. A manutenção de níveis altos de investimento público e pleno emprego ao longo do tempo é recusada fortemente por colocar os trabalhadores fora do campo de ação dos capitães da indústria quando estes estiverem desejosos de "dar-lhes uma lição". Este tipo de articulação entre a dinâmica do investimento capitalista e a ação econômica dos governos configura, assim, um "ciclo econômico político" no qual o "clima dos negócios" é a variável "reguladora" permanente que assegura a internalização da "norma" pelos trabalhadores. Por analogia, podemos dizer que o estado de laissez faire assegura a capacidade dos investidores "darem lição" também aos atores sociais de áreas onde têm interesse em investir, fazendo da promessa de empregos o meio de obter vantagens locacionais e livre acesso a recursos ambientais. Cabe ressaltar que as reformas neoliberais não consistiram, como no liberalismo de Adam Smith, na introdução do mercado como espaço de liberdade na sociedade política, mas, sim, no fato de remeter, referir, projetar em uma arte geral de governar os princípios formais de uma economia de mercado (Foucault, 2007, p. 158).
} 
si, os grandes empreendimentos tornam-se também "quase-sujeitos" dos limites de aceitabilidade dos riscos sociais e ambientais para a própria população. O processo de construção, por parte dos atores, do que se entende por "intolerável" e "arriscado" (Fassin e Bourdelais, 2005) ver-se-á, via de regra, constrangido pelas condições impostas pelas empresas.

\section{O campo científico e o embate entre questões}

O campo da ciência define-se por um conjunto de posições e relações através das quais os agentes nele atuantes concorrem pelo poder de estabelecer o que é e o que não é científico, quais são os temas relevantes, os objetos e métodos legítimos de pesquisa. Neste campo defrontamse construções sociais concorrentes, representações que se pretendem fundadas numa "realidade" que se supõe capaz de validar os métodos coletivamente acumulados (Bourdieu, 1975). Os agentes e instituições presentes no campo disputam, assim, a definição do tipo de ciência que deve ser feito, o que é atual e o que é ultrapassado.

Neste campo científico, em sua matriz tecnologicamente induzida, as ciências duras são, hoje, no Brasil, convocadas a fornecer soluções as mais eficientes para a inserção dos territórios nos circuitos da acumulação, em nome do fortalecimento da "nação" como ente geoeconômico, ignorando, porém, com frequência, a multiplicidade de sujeitos, culturas e projetos que habitam - e significam - os espaços atravessados crescentemente por redes técnicas de exploração e circulação de mercadorias. Agindo sobre o âmbito das ciências sociais, por sua vez, são cada vez mais comuns os programas empresariais que envolvem profissionais formados em tais disciplinas em dinâmicas de acompanhamento e, em certos casos, de neutralização da capacidade critica da sociedade. Atividades de relações comunitárias, de "monitoramento de populações do entorno" 
e estudos ditos de "risco social" procuram se antecipar à possibilidade de que movimentos sociais organizem populações atingidas por grandes empreendimentos, identificando lideranças, estimando o estado da imagem das empresas junto aos grupos sociais com que têm alguma relação de proximidade físico-territorial - e, em consequência, potencialmente política, tendo em vista a localização de monocultivos, equipamentos e instalações. Aproveitando-se do vazio do Estado na garantia de direitos como saúde e educação, as grandes empresas procuram, crescentemente, legitimar os danos que causam oferecendo como favor aquilo que é dever do Estado. Programas ditos de responsabilidade social procuram aumentar o "estoque de capital reputacional" das empresas, buscando obter o que elas entendem por "licença social para operar"7. Conforme relata um executivo de grande mineradora multinacional na Amazônia: "- Antes os movimentos sociais nos criticavam dizendo que deixávamos na região apenas um buraco. Agora, é diferente, deixamos também uma escola ou um posto de saúde". A resistência dos movimentos populares também dará lugar a novas categorias usadas na gestão empresarial, tais como as de "custo indígena e custo quilombola", que procuram designar, na contabilidade do capital, os recursos necessários para que as empresas se previnam dos eventuais prejuízos previstos em razão da ação dos sujeitos localizados em territórios e mobilizados por se verem como objeto de expropriação. A

\footnotetext{
${ }^{7} \mathrm{~A}$ intervenção das firmas na gestão do território não representa uma novidade. A novidade reside nas modalidades de saída de crises institucionais - no caso, as reformas neoliberais que permitem uma participação crescente das firmas na gestão do território. Alguns autores insistem, a propósito, no aspecto residual dos processos eleitorais em situações de "governança" em que os atores privados assumem um maior espaço de decisão (Amilhat Szary, 2010). Outros chamam a atenção para o fato de que as corporações, com suas políticas territoriais, procuram produzir resignação pretendendo oferecer respostas às críticas que lhes são endereçadas (Benson, Kirsch, 2010).
} 
persistência da resistência no tempo explicará também o que os mesmos contabilistas designam por recusto indígena e quilombola ${ }^{8}$.

Há, por sua vez, desqualificação do próprio debate, quando as pesquisas propõem-se a levar em conta a perspectiva própria dos "de baixo". Exemplo: discussões que apontam a vulnerabilidade social como uma relação e não uma carência, não podendo a mesma ser atacada eficazmente através da oferta compensatória de bens ou de supostas competências gerenciais, como sugerem os programas das agências multilaterais, e que sustentam que seria preciso interromper os processos que concentram os riscos sobre os mais desprotegidos são consideradas como expressão de discussões do passado, incompatíveis com o atual estágio dito de neodesenvolvimento. A perspectiva dos de baixo é, com frequência, considerada do atraso, e a dos de cima, a do avanço (Acselrad, 2013).

Há que se considerar igualmente processos que se constituem no entremeio dos dois campos - político e científico. No que diz respeito aos impactos negativos dos grandes projetos, por exemplo, temos visto prevalecer, de forma clara, uma lógica utilitária com relação à incerteza científica; ou seja, a adoção de formas oportunistas de apropriação social da incerteza, via de regra como elemento constitutivo do que Beck (1992) chama de irresponsabilidade organizada - a desresponsabilização de tomadores de decisão, a postergação de eventual responsabilização e de adoção de medidas, a transferência de responsabilidade para as vítimas, ou, no caso brasileiro, a adoção de termos de ajuste de conduta que acomodam a transgressão legal, alegando-se a ausência de relações causais certificadas etc. ... Tal irresponsabilidade é, ademais, via de regra, de classe, dados os indicadores sociais característico de suas vítimas mais correntes (Coletivo, 2013).

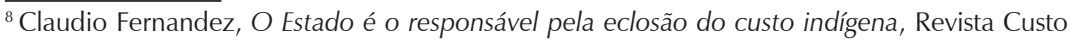
Brasil, 2009, Modal Informática, Rio de Janeiro. Disponível em: <http://www.revistacustobrasil.com.br/pdf/06/Rep\%2003.pdf>. Acesso em 10 mai. 2010. 
Uma para-ciência etnocêntrica dos impactos é, por seu turno, acionada sistematicamente, desconsiderando a presença de povos e comunidades tradicionais no território, levando em conta apenas as relações formais de propriedade da terra, ignorando áreas de uso comum e o pluralismo jurídico vigente, notadamente, nas áreas de fronteira de expansão do mercado e do capital. Em contrapartida, são vários os casos de restrição à liberdade acadêmica e de perseguição de pesquisadores quando estes tratam de estudar o impacto dos projetos de desenvolvimento sobre as práticas espaciais e as condições de reprodução de grupos sociais subalternos: processos judiciais foram abertos contra pesquisadores que mostraram danos ambientais causados por uma empresa às águas de uma Terra Indígena e por projetos turísticos irregulares do ponto de vista da ocupação de áreas litorâneas; campanhas públicas com ameaças contra uma pesquisadora que elaborou parecer crítico sobre o EIA (Estudo de Impacto Ambiental) de uma empresa siderúrgica no Mato Grosso; ação contra profissionais da Geografia e Ciências Sociais que coordenaram os estudos de reconhecimento de territórios quilombolas no norte do Espírito Santo, alegando que os mesmos não possuíam credibilidade técnica/ profissional por não serem neutros na questão do reconhecimento dos territórios quilombolas; interpelações judiciais, interditos proibitórios, pressões por descredenciamentos profissionais, presença de executivos de grandes corporações em defesas de teses acadêmicas para constranger orientandos e orientadores são algumas das outras práticas que ilustram a desigualdade de forças entre os que empreendem esforços acadêmicos autônomos e o poder econômico (Giffoni Pinto, 2013).

Como interpretar este contexto? De forma simplificada, valeria considerar pelo menos duas das abordagens com maior visibilidade na Sociologia das ciências. A abordagem - por vezes, conspiratória - dos interesses alega que um complexo acadêmico-industrial é mobilizado em 
nome da competitividade das economias nacionais na globalização: o IPCC - International Pannel on Climatic Change - e demais painéis científicos refletiriam os interesses dos poderosos e das empresas internacionais de consultoria, promovendo uma agenda que lhes é própria e obscurecendo as desigualdades políticas na responsabilidade pela degradação ambiental e social (Buttel; Taylor, 1992; Bohemer-Christensen, 1994). A eventual evocação da complexidade dos objetos socio-ecológicos serviria para justificar políticas intensivas em pesquisa e alimentar os orçamentos em ciência e tecnologia. A abordagem das propriedades culturais da ciência, por sua vez, considera que, dada a incerteza científica quanto aos processos de transformação socio-ecológica, as condições de validade, os compromissos sociais e morais da ciência expõem-se ao debate com a sociedade. Instaura-se uma negociação sobre os limites socioculturais da ciência; a incerteza científica é o alimento para o amadurecimento do processo social de aprendizagem sobre estes limites (Fabiani, 1997; Wynne, 1994). Redefinem-se as relações entre Ciências Naturais e Ciências Sociais - as primeiras se estariam historicizando; reconhecem-se múltiplas escalas de observação; as descrições são consideradas "mortais"; admitem-se respostas múltiplas a uma questão única. Haveria aspectos éticos e políticos envolvidos na discussão, mas também questões propriamente epistemológicas: a evidenciação da incerteza não exprime o reconhecimento de uma impotência do saber racional, mas sim uma redefinição de seus critérios de produtividade; redefine-se, assim, o que se pode esperar socialmente da produção científica (Fabiani, 1997, p. 305). Paradoxalmente, a norma regulatória estabelecida pelos governos instaura reflexividade e não acordo. Ressalta-se o fato de que o mundo é visto como um laboratório aberto à mídia, embora mais opaco do que nunca: quanto maior a informação maior a indeterminação das ações a empreender; crescem, em permanência, os problemas levantados técnica 
e moralmente e reduzem-se, por outro lado, os meios de ação disponíveis. A incerteza, assim, tenderia a se reproduzir: o saber especializado não é mais capaz de fechar o debate, mas sim de abri-lo em termos de valores, considerada a perícia como uma ilusão necessária que resulta numa negociação infindável sobre valores (Fabiani, 1997).

Ora, na América Latina, a lógica das coisas não estaria apontando na direção dessa postura reflexiva, tal como apontada na literatura dos estudos culturais da ciência desenvolvidos em outros continentes. Na relação entre campo científico e campo político, podemos reconhecer o recurso a argumentos científicos para legitimar decisões previamente tomadas a respeito de marcos regulatórios de determinados objetos tecnocientíficos e não vemos desenvolver-se uma discussão sobre as modalidades, específicas a nosso contextos culturais e políticos, pelas quais a incerteza científica é apropriada socialmente. Quando resultados de pesquisa parecem ameaçar as condições esperadas de rendimento dos investimentos - porque se supõe a pertinência da alteração de projetos, mudanças de localização etc. - a acusação pode assumir uma dimensão judicial, destinada a dissuadir, desprestigiar, constranger, impedir ou paralisar o trabalho de pesquisa, e, consequentemente, o "debate sobre valores". Quando a ciência questiona o empreendimento, o único valor que parece ter-se em conta é "o valor". Assim, a lógica do interesse tem, de fato, constrangido as possibilidades de se evidenciar as dimensões culturais dos debates no campo das ciências.

\section{Considerações finais}

De fato, cada vez mais, políticas de conhecimento se entrelaçam com políticas "de desenvolvimento", de ocupação territorial e de legitimação das escolhas técnicas - seja no caso da transgenia, das formas 
de energia, dos impactos de grandes projetos minerários ou hidrelétricos. Nas políticas de conhecimento, operam distintas lógicas na inscrição social das disputas cognitivas: há os que esperam que o conhecimento "posto em questão" favoreça o crescimento da própria ciência (e, podemos supor, consequentemente, do papel social dos próprios cientistas); há os que esperam que os litígios cognitivos permitam melhor conhecer os processos de conhecimento, abrindo, permanentemente, a partir dos próprios questionamentos, novas e desafiadoras questões (é o caso de filósofos da ciência ou do conhecimento); há os que esperam que os conflitos cognitivos favoreçam o aperfeiçoamento das práticas de governo, seja pela convergência de pesquisas científicas metodologicamente plurais sobre mesmos objetos, seja pela complementação que, eventualmente, se admita vir em proveniência do saber leigo (é o caso dos agentes da racionalização das decisões do Estado, assim como da ciência dita evidence-based); há os que esperam melhor defenderem-se dos riscos e danos que lhes são impostos, tendo por base o que lhes é apresentado - a seu ver suspeitosamente - como seguro, de acordo com o conhecimento perito, opondo-se-lhes elementos de uma epistemologia leiga, contextual e situada (é o caso das comunidades que se consideram afetadas por projetos econômicos ou decisões políticas com fortes - e frequentemente inigualitárias - implicações territoriais e ambientais) (Funtowicz e Ravetz, 1991); há, por fim, os que se envolvem nas lutas cognitivas para desconstruir as epistemologias etnocêntricas e evidenciar as dimensões políticas do campo do conhecimento (tratam-se dos sujeitos epistêmicos da democratização dos poderes cognitivos: ao lado da ecologia dos saberes pretendem, igualmente, uma ecologia dos poderes). Evidencia-se, assim, que o "saber leigo", dito com "objetividade de segundo grau", é também um saber que tem uma perspectiva histórica - não determinística - dos processos.

As empresas não são Deus; assim como vieram, elas podem voltar, afirmou uma senhora quilombola de uma região que passou a ser ocupada por 
monoculturas de eucalipto 9 . Este saber leigo - dito "situado" pelos estudos culturais da ciência - não é simplesmente um saber que complementa e democratiza a decisão no plano cognitivo; é também um saber político que situa os demais sujeitos, inclusive o sujeitos epistêmicos dominantes. Assim afirmou um trabalhador rural atingido por barragem sobre sua participação em fóruns participativos de avaliação da política de barragens no âmbito da WCD - Comissão Mundial de Barragens: - aprendo muito nestas reuniões; aprendo o que é meio ambiente, o que é biodiversidade etc.; mas aprendo, sobretudo, a separar quem presta de quem não presta ${ }^{10}$. Ou seja, a persistência de uma tal capacidade crítica - exemplificada pelas citações acima - mesmo em condições de forças tão adversas, é o que poderia explicar o esforço permanentemente empreendido pelos poderes para desenvolver inovações institucionais e discursivas destinadas a dissolver ou obscurecer a incerteza que a crítica produz a respeito da pertinência da realidade como ela é, sobre o que importa e sobre o que tem valor.

Henri Acselrad. Mestre em Economia pela Université Paris 1 (Panthéon-Sorbonne) e Doutor em Planejamento, Econ. Pública e Org. do Território pela Université Paris 1 (Panthéon-Sorbonne) (1980). Atualmente é Professor Associado do Instituto de Pesquisa e Planejamento Urbano e Regional da Universidade Federal do Rio de Janeiro. $\gg$ hacsel@uol.com.br

\footnotetext{
${ }^{9}$ Entrevista a Raquel Giffoni Pinto, in $\mathrm{H}$. Acselrad (coord.), O movimento de resistência à monocultura do eucalipto no Norte do Espírito Santo e Extremo Sul da Bahia - uma sociologia da recusa e do consentimento em contexto de conflito ambiental, Relatório de Projeto Integrado de Pesquisa - CNPq; Rio de Janeiro, mimeo. 2010.

${ }^{10}$ Entrevista ao autor, Belém do Pará, 2000.
} 
Sociologias, Porto Alegre, ano 16, no 35, jan/abr 2014, p. 84-105

\section{Referências}

1. ACSELRAD, H. (Coord.) $\mathbf{O}$ movimento de resistência à monocultura do eucalipto no Norte do Espírito Santo e Extremo Sul da Bahia - uma sociologia da recusa e do consentimento em contexto de conflito ambiental. 2010. 150 f. Relatório de Projeto Integrado de Pesquisa - CNPq, mimeo, Rio de Janeiro.

2. ACSELRAD, H. O conhecimento do ambiente e o ambiente do conhecimento - anotações sobre a conjuntura do debate sobre vulnerabilidade, Em Pauta, v. 11, n. 32, 2013.

3. ACSELRAD, H.; BEZERRA, G. N. Desregulação, deslocalização e conflito ambiental: considerações sobre o controle de demandas sociais. In: ALMEIDA, A.W.B et all. Capitalismo globalizado e recursos territoriais - fronteiras da acumulação no Brasil contemporâneo. Rio de Janeiro: Ed. Lamparina, 2010. p. 179-210.

4. AMILHAT SZARY, A-L. La prise de position des acteurs privés dans la gouvernance terrioriale: enjeux, opportunités, risques. In: AMILHAT SZARY, A-L. Les Acteurs privés dans la gouvernance en Amérique Latine: firme et terrritoire en Amérique Latine. Paris: Institut de Recherche et Débat sur la Gouvernanc, 2010. p. 6-16.

5. BECK, U. From Industrial Society to Risk Society: questions of survival, social structure and ecological enlightenment. Theory, Culture \& Society, v. 9, p. 97123, 1992.

6. BENSON, P.; KIRSCH, S. Capitalism and the politics of resignation, Current Anthropology, Chicago, n. 51 (4), August, p.459-486, 2010.

7. BOEHMER-CHRISTENSEN, S. Global climate protection policy: the limits of scientific advice, Global Environmental Change, n. 4 (2), p.140-159, 1994.

8. BOLTANSKI, L. De la critique. Paris: Gallimard, 2009.

9. BOURDIEU, P. Os usos sociais da ciência. São Paulo: Ed. UNESP/INRA, 2003.

10. BOURDIEU, P. La spécificité du champ scientifique et les conditions sociales du progrès de la raison, Sociologie et sociétés, vol. 7 n.1, p. 91-118, 1975.

11. BUTTEL, F.; TAYLOR, P. J. Environmental sociology and global environmental change: a critical reassessment, Society and Natural Resources, University of Wisconsin, Madison, n. 5, p. 211-230, 1992.

12. CARDOSO de OLIVEIRA, R. Entrevista concedida a Carlos Fausto e Yonne Leite (Museu Nacional/UFRJ) e Carmen Weingrill e Vera Rita da Costa (Ciência Hoje). Disponível em: <http://www.canalciencia.ibict.br/notaveis/livros/roberto_cardoso_de_oliveira_39.html>.Acesso em: 3 dez. 2013. 
13. COLETIVO brasileiro de pesquisadores da desigualdade ambiental. Desigualdade ambiental e acumulação por espoliação: o que está em jogo na questão ambiental, in e-cadernos CES, n. 17, 2013, p. 190-20. Disponível em: < http:// www.ces.uc.pt/e-cadernos/pages/pt/indice.php>. Acesso em: 10 dez. 2013.

14. DESCOMBES, V. Quand la mauvaise critique chasse la bonne..., Tracés - revue de sciences humaines, Présent et futur de la critique, ENS Éditions, Lyon, hors-série, 45-69, 2008.

15. EWALD, F. Foucault - a norma e o direito. Lisboa: Vega, 1997.

16. FABIANI, J-L. Principe de Précaution et Protecion de la Nature. In: GODARD, O. (Org.). Le Principe de Précaution dans la Conduite des Affaires Humaines. Paris: INRA, 1997. p. 297-310.

17. FASSIN, D.; BOURDELAIS, P. Les Constructions de I’intolérable - études $\mathbf{d}^{\prime}$ anthropologie et $\mathbf{d}^{\prime}$ histoire sur les frontières de I'espace moral. Paris: La Découverte, 2005.

18. FERNANDEZ, C. O Estado é o responsável pela eclosão do custo indígena, Revista Custo Brasil, São Paulo, Modal Informática, Rio de Janeiro, 2009. Disponível em: < http://www.revistacustobrasil.com.br/pdf/06/Rep\%2003.pdf>. Acesso em: 10 mai. 2010.

19. FOUCAULT, M. El nacimiento de la biopolítica. México: Fondo de Cultura Económica, 2007.

20. FUNTOWICZ, S. O.; RAVETZ, J. R. A New scientific methodology for global environmental issues. In: CONSTANZA, R. (ed.) Ecological Economics, New York, Columbia University Press, New York, p.137-152, 1991.

21. GABORIAU, P. Le Chercheur et la politique - I'ombre de nouveaux inquisiteurs. Paris: Aux lieux d'être, 2008.

22. GIFFONI PINTO, R. A pesquisa sobre conflitos ambientais e o assédio processual a pesquisadores no Brasil. Rio de Janeiro: IPPUR/UFRJ, 2013.

23. GUEDES, A. D. Lutas por Terra e Lutas por Território nas Ciências Sociais Brasileiras: Fronteiras, Conflitos e Movimentos. In: ACSELRAD, Henri (Org.). Cartografia social, terra e território, ETTERN/IPPUR/UFRJ, Coleção Território, ambiente e conflitos sociais n.3, Rio de Janeiro, p.41-80, 2013.

24. GONZÁlEZ CASANOVA, P. La democracia en México. México: Ediciones ERA, 1965.

25. GONZÁLEZ CASANOVA, P. Sociología de la explotación. México: Siglo XXI Editores, 1987. [1969]. 
26. GONZÁLEZ CASANOVA, P. Colonialismo interno (uma redefinição). In: BORON, A. A.; AMADEO, J.; GONZALEZ, S. A teoria marxista hoje. Problemas e perspectivas, 2007, ISBN 978987118367-8. Disponível em: <http://bibliotecavirtual.clacso.org.ar/ar/libros/campus/marxispt/cap. 19.doc >. Acesso em: 3 dez. 2013.

27.HARVEY, D. O Novo Imperialismo. São Paulo: Ed. Loyola, 2004.

28. KALECKI, M. Aspectos Políticos do Pleno Emprego. In: MIGLIOLI, J. (Org.) Crescimento e Ciclo nas Economias Capitalistas. São Paulo: Ed. Hucitec, 1983 [1943]. p. 54-60.

29. LERNER, A. P. The Economics and politics of consumer sovereignty. American Economic Review, Pittsburgh, n. 62, p. 258-266, May, 1972.

30. MAGAlHÃES, S. M. S. B.; HERNANDEZ, F. M. (Org.). Painel de Especialistas - Análise Crítica do Estudo de Impacto Ambiental do Aproveitamento Hidrelétrico de Belo Monte. Belém, 2009.

31. MALTA CASTO, M. I.; GALETTI, G.; LILIA de S. Diagnóstico e avaliação do setor florestal brasileiro - Mato Grosso - Histórico dos usos dos recursos florestais em Mato Grosso. Cuiabá: ITTO-Ibama-Funatura, 1994.

32. OST, F. La Crise Écologique: vers un nouveau paradigme? Contribution d'un juriste à la pensée du lien et de la limite. In: LARRÈRE, C. - LARRÈRE, R. (Orgs.), La Crise Environnementale, Paris: INRA, 1994. p. 39-56

33. PALACIOS, G. Naturaleza en disputa. Ensayos de historia ambiental de Colombia. Bogotá: Universidad Nacional de Colombia- Colciencias- Icanh, 2001.

34. SAID, E. W. Falar a verdade ao poder. In: SAID, E. W. Representações do intelectual, as conferências Reith de 1993, Cia. das Letras, São Paulo, p. 89-104, 2005.

35. STENGERS, I. Science et Pouvoir. Brixelles: Ed. Labor, 1997.

36. STENGERS, I.; PHILIPPE, P. La Sorcellerie Capitaliste. Paris: La Découverte, 2005.

37. WRIGHT MILLS, The Problem of Industrial Development in HOROWITZ, Irving L. (eds.) Power, Politics and People, Nova lorque, Oxford University Press, p. $154,1963$.

38. WYNNE, B. Scientific Knowledge and the Global Environment. In: REDCLIFT, M.; BENTON, T. (eds.). Social Theory and the Global Environment, Routledge, NY, p. 169-189, 1994.

Recebido em: 13/08/2013

Aceite final:16/12/2013 